\title{
Experimental Research \\ Effects of intraventricular infusion of vascular endothelial growth factor on cerebral blood flow, edema, and infarct volume*
}

\author{
M. R. Harrigan, S. R. Ennis, S. E. Sullivan, and R. F. Keep \\ Department of Neurosurgery, University of Michigan Health System, Ann Arbor, Michigan, U.S.A.
}

Published online January 14, 2003

(C) Springer-Verlag 2003

\section{Summary}

Background. Therapeutic cerebral angiogenesis, utilizing angiogenic factors to enhance collateral vessel formation within the central nervous system, is a potential method for cerebral revascularization. A prior dose-response study determined that intracerebroventricular infusion of vascular endothelial growth factor (VEGF) increases vascular density with minimal associated brain edema at a concentration of $5 \mu \mathrm{g} / \mathrm{ml}$. The purpose of this study was to assess effects of intracerebroventricular infusion of VEGF $(5 \mu \mathrm{g} /$ $\mathrm{ml}$ ) on cerebral blood flow, infarct volume, and brain edema after ischemia.

Methods. Recombinant human $\mathrm{VEGF}_{165}$ was infused into the right lateral ventricle of rats with an osmotic minipump at a rate of $1 \mu \mathrm{l} / \mathrm{hr}$ for 7 days. Control animals received vehicle only. Ischemia was produced by transient ( 2 hours) middle cerebral artery occlusion (MCAO). After MCAO, cerebral blood flow was determined with the indicator fractionation technique: infarct volume was assessed with 2,3,5-triphenlytetrazolium chloride staining, and brain edema was determined by measuring brain water content

Findings. Cerebral blood flow was not significantly different in animals treated with VEGF compared to controls. There was a significant reduction in total infarct volume after temporary MCAO in VEGF-treated animals compared to controls $\left(163 \pm 37 \mathrm{~mm}^{3}\right.$ vs. $\left.309 \pm 54 \mathrm{~mm}^{3}, P<0.05\right)$. Brain water content after transient MCAO was also significantly reduced in VEGF-treated animals compared to controls $(80.9 \pm 0.7 \%$ vs. $83.3 \pm 0.6 \%, P<0.05)$.

Interpretation. Intracerebroventricular infusion of $\mathrm{VEGF}_{165}$ $(5 \mu \mathrm{g} / \mathrm{ml})$ decreases infarct volume and brain edema after temporary MCAO without a significant increase in cerebral blood flow. These results indicate that VEGF may have a direct neuroprotective effect in cerebral ischemia.

Keywords: Angiogenesis; vascular endothelial growth factor; brain edema; cerebral ischemia.

* This work was funded by a Pharmacia Upjohn Cerebrovascular Fellowship Award to Dr. Harrigan and an internal grant from the Department of Surgery, University of Michigan Health System.

\section{Introduction}

Therapeutic angiogenesis, utilizing angiogenic factors to augment collateral circulation, is an active area of investigation for patients with peripheral arterial occlusive disease [2] and myocardial ischemia [8, 11, 12]. For patients with cerebral hemodynamic compromise, provision of angiogenic factors to the brain may be a viable method to augment current methods of surgical and endovascular cerebral revascularization. Most research in therapeutic angiogenesis has centered on vascular endothelial growth factor (VEGF) [3, 21]. VEGF is a powerful endothelial mitogen that also increases vascular permeability. Plans for the use of VEGF in the central nervous system must consider both effects on angiogenesis as well as the potential for brain edema formation.

Intracerebral injection of VEGF leads to the formation of a cluster of abnormal-appearing blood vessels [13]. A dose-response study in this laboratory utilizing intraventricular infusion of $\mathrm{VEGF}_{165}$ at a rate of $1 \mu \mathrm{l} / \mathrm{hr}$ for 7 days at several different concentrations found that a concentration of $5 \mu \mathrm{g} / \mathrm{ml}$ was the minimum concentration required to produce a significant increase in vessel density in the rat [4]. At $5 \mu \mathrm{g} / \mathrm{ml}$, there was an increase of 17 to $21 \%$ in vessel density in the cerebral cortex compared to control animals infused with vehicle only. At this dose there was also an increase in capillary permeability, which was limited to the diencephalon ipsilateral to the infusion, but brain water content was not significantly in- 
creased. A higher dose of $25 \mu \mathrm{g} / \mathrm{ml}$ produced a greater increase in vascular density, but also led to significant ventriculomegaly, possibly due to a VEGF-induced increase in cerebrospinal fluid production.

This study was designed to examine whether the limited degree of angiogenesis induced by intraventricular infusion of $5 \mu \mathrm{g} / \mathrm{ml}$ of $\mathrm{VEGF}_{165}$ would be sufficient to increase cerebral blood flow during middle cerebral artery occlusion in the rat and reduce infarct volume. In addition, it also examined whether any such beneficial effect might be offset by increased cerebral edema.

\section{Methods and material}

Procedures using laboratory animals were approved by the Institutional Animal Care and Use Committee.

\section{VEGF infusion}

Osmotic minipumps designed to deliver $1 \mu \mathrm{l} / \mathrm{hr}$ for 7 days (Model 2001, Alza) were filled with a solution containing human recombinant VEGF $_{165}$ (Sigma) in $0.1 \mathrm{M}$ PBS with $0.1 \%$ BSA, and each was attached to a brain infusion cannula. $\mathrm{VEGF}_{165}$ was infused at a concentration of $5 \mu \mathrm{g} / \mathrm{ml}$. Control pumps contained the vehicle only. The filled pumps were primed by incubation overnight in sterile saline. Adult Sprague-Dawley rats (219-230 g) were anesthetized with intraperitoneal ketamine $(50 \mathrm{mg} / \mathrm{kg})$ and xylazine $(10 \mathrm{mg} / \mathrm{kg})$. After a skin incision over the center of the skull, a pocket was formed over the neck and scapulae to hold the minipump. A $2 \mathrm{~mm}$ hole was drilled in the skull $0.6 \mathrm{~mm}$ posterior to the coronal suture and $1.2 \mathrm{~mm}$ to the right of the sagittal suture. The cannula was placed in the brain to a depth of $4.5 \mathrm{~mm}$ from the outer surface of the skull, and a sterile screw was inserted. The cannula was cemented in place and the incision was sutured. After 1 week, the animals were anesthetized for middle cerebral artery occlusion (MCAO).

\section{Middle cerebral artery occlusion}

Temporary ( 2 hours) occlusion of the middle cerebral artery (MCA) was achieved using the suture method of Longa and colleagues [7]. Briefly, anesthesia was induced with intraperitoneal administration of pentobarbital $(50 \mathrm{mg} / \mathrm{kg})$. Body temperature, but not brain temperature, was maintained at $37^{\circ} \mathrm{C}$, and no artificial ventilation was used. The bifurcation of the common carotid artery was exposed and the external carotid artery was ligated distally. A 3-0 monofilament nylon suture, its tip rounded by heating, was introduced into the internal carotid artery lumen through the stump of the external carotid artery and gently advanced into the internal carotid artery $19-20 \mathrm{~mm}$ past the common carotid artery bifurcation to block the origin of MCA. After 2 hours of MCA occlusion, reperfusion was achieved by withdrawal of the suture from external carotid artery. After closing the skin incision, rats were allowed to recover from anesthesia, returned to their cages, and allowed to move and eat freely.

\section{Morphometric measurement of infarct volume}

Animals were sacrificed 24 hours after temporary MCAO, and the infarcted brain tissue was identified by mitochondrial staining with
2\% 2,3,5-triphenlytetrazolium chloride (TTC) solution. Brain tissue was incubated in TTC for one hour. The area of infarction in each slice was analyzed by a computerized image analysis system, and the volume of infarction was calculated by multiplying the distance between sections [19].

\section{Cerebral blood flow measurement}

After 7 days of VEGF infusion, rats underwent temporary MCAO. Twenty-four hours after MCAO, animals not undergoing TTC measurement of infarct volume were reanesthetized with pentobarbital and cerebral blood flow $(\mathrm{CBF})$ was determined. Cerebral blood flow was measured by the indicator fractionation technique [17] using $\left[{ }^{14} \mathrm{C}\right]-\mathrm{N}$-isopropyl-p-iodoamphetamine ([ $\left.{ }^{14} \mathrm{C}\right] \mathrm{IMP}$; American Radiolabeled Chemicals [18]). This method uses an intravenous bolus injection of a blood flow indicator followed by a constant rate of blood withdrawal through a femoral artery catheter to obtain the integral of the arterial isotope concentration. The withdrawal was started 5 seconds before intravenous injection of $5 \mu \mathrm{Ci}$ of $\left[{ }^{14} \mathrm{C}\right] \mathrm{IMP}$. Two minutes later, the animal was killed by decapitation and blood withdrawal was stopped. The sample of withdrawn arterial blood was bleached with $30 \% \mathrm{H}_{2} \mathrm{O}_{2}$ prior addition of scintillation fluid and counting using a Beckman 3801 liquid scintillation counter. The brain was divided into core, intermediate, and outer regions. The core and intermediate regions correspond roughly to the core and penumbra of the infarction [9]. The sections were then digested in methylbenzethonium hydroxide prior to counting.

Blood flow rates for the individual pieces of brain tissue were calculated using the following equation:

$$
\mathrm{Fb} / \mathrm{Mb}=\mathrm{Qb}(\mathrm{T}) \cdot \mathrm{Fs} / \mathrm{Qs}(\mathrm{T}) \cdot \mathrm{Mb}
$$

where $\mathrm{Fb}=$ the brain blood flow; $\mathrm{Mb}=$ the brain mass (in grams); $\mathrm{Qb}(\mathrm{T})=$ the quantity of indicator in the tissue at time $\mathrm{T} ; \mathrm{Fs}=$ the rate of blood withdrawal from $\mathrm{t}=0$ to $\mathrm{t}=\mathrm{T}$; $\mathrm{Qs}(\mathrm{T})=$ the quantity of indicator present in the withdrawal at time T. Cerebral blood flow is expressed as $\mathrm{ml} / \mathrm{g} / \mathrm{min}$.

\section{Brain water content}

Following infusion of VEGF or vehicle and 24 hours after $\mathrm{MCAO}$, rats not undergoing infarct volume or CBF measurement were anesthetized and killed by decapitation. The brain was removed rapidly and divided into cortex and basal ganglia. Cortices were flattened on a piece of Parafilm and punches were made of ipsilateral and contralateral cortices to obtain tissue samples from the core of the MCA distribution, a ring of tissue surrounding these, hereafter called the intermediate zone, and the remainder of the cortex, hereafter called the outer zone [9]. The samples were weighed and then dried at $95^{\circ} \mathrm{C}$ for 24 hours to obtain the dry weight. The brain water content was calculated as (wet weight - dry weight)/dry weight.

\section{Statistical analysis}

All data are expressed as means \pm SE. The two-tailed unpaired Student's $t$ test was used for all evaluations. Statistical significance was accepted at $P<0.05$.

\section{Results}

All animals were treated with either VEGF or vehicle. After a seven-day infusion period, the animals then underwent temporary MCAO, followed 24 hours later by measurement of either cerebral blood flow, infarct volume, or brain water content. 
Table 1. Physiological parameters of rats during cerebral blood flow experiments

\begin{tabular}{lcllll}
\hline Group & $\begin{array}{l}\mathrm{MABP}, \\
\mathrm{mmHg}\end{array}$ & $\mathrm{pH}$ & $\begin{array}{l}\mathrm{pCO}_{2}, \\
\mathrm{mmHg}\end{array}$ & $\begin{array}{l}\mathrm{pO}_{2}, \\
\mathrm{mmHg}\end{array}$ & $\begin{array}{l}\text { Hematocrit, } \\
\%\end{array}$ \\
\hline Vehicle & $96 \pm 9$ & $7.40 \pm 0.03$ & $52 \pm 4$ & $74 \pm 11$ & $42 \pm 3$ \\
VEGF & $106 \pm 17$ & $7.42 \pm 0.03$ & $49 \pm 5$ & $67 \pm 7$ & $44 \pm 2$ \\
\hline
\end{tabular}

MABP indicates mean arterial blood pressure. Values are expressed as mean \pm SE for 5 animals in each group.

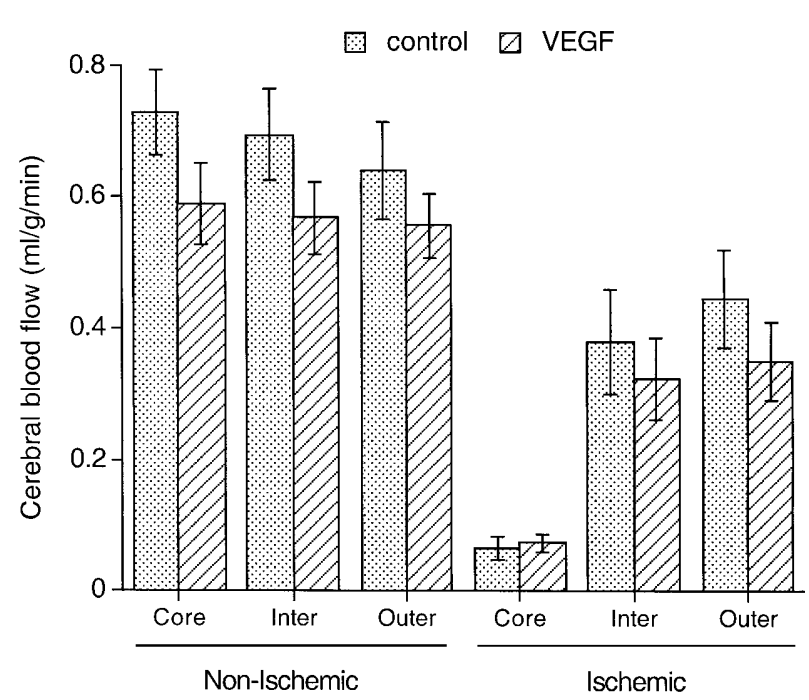

Fig. 1. Bar graph showing cerebral blood flow 24 hours after temporary MCAO in animals treated with intraventricular infusion of VEGF or vehicle ( $n=5$ in each group). Values are mean \pm SE

\section{Cerebral blood flow}

Cardiovascular and respiratory parameters during cerebral blood flow measurements were all within the normal range (Table 1). Cerebral blood flow was measured in the non-ischemic as well as the ischemic hemisphere, and was not significantly different between animals treated with VEGF or vehicle (Fig. 1).

\section{Infarct volume}

Infarct volume was measured in animals following temporary middle cerebral artery occlusion after treatment with VEGF or vehicle. Cardiovascular and respiratory parameters during $\mathrm{MCAO}$ were all within the normal range (Table 2). After temporary MCAO, the infarct volumes were significantly smaller in the group treated with VEGF (Fig. 2). In the VEGF group, the total infarct volume was $163 \pm 37 \mathrm{~mm}^{3}$, whereas in the vehicle group it was $309 \pm 54 \mathrm{~mm}^{3}$ $(P<0.05)$. When the infarct volumes were divided
Table 2. Physiological parameters of rats during middle cerebral artery occlusion experiments

\begin{tabular}{llllll}
\hline Group & $\begin{array}{l}\mathrm{MABP}, \\
\mathrm{mmHg}\end{array}$ & $\mathrm{pH}$ & $\begin{array}{l}\mathrm{pCO}_{2}, \\
\mathrm{mmHg}\end{array}$ & $\begin{array}{l}\mathrm{pO}_{2}, \\
\mathrm{mmHg}\end{array}$ & $\begin{array}{l}\text { Hematocrit, } \\
\%\end{array}$ \\
\hline Vehicle & $99 \pm 2$ & $7.46 \pm 0.04$ & $47 \pm 4$ & $81 \pm 4$ & $42 \pm 2$ \\
VEGF & $95 \pm 5$ & $7.46 \pm 0.06$ & $53 \pm 8$ & $71 \pm 12$ & $41 \pm 5$ \\
\hline
\end{tabular}

MABP indicates mean arterial blood pressure. Values are expressed as mean \pm SE for each group.

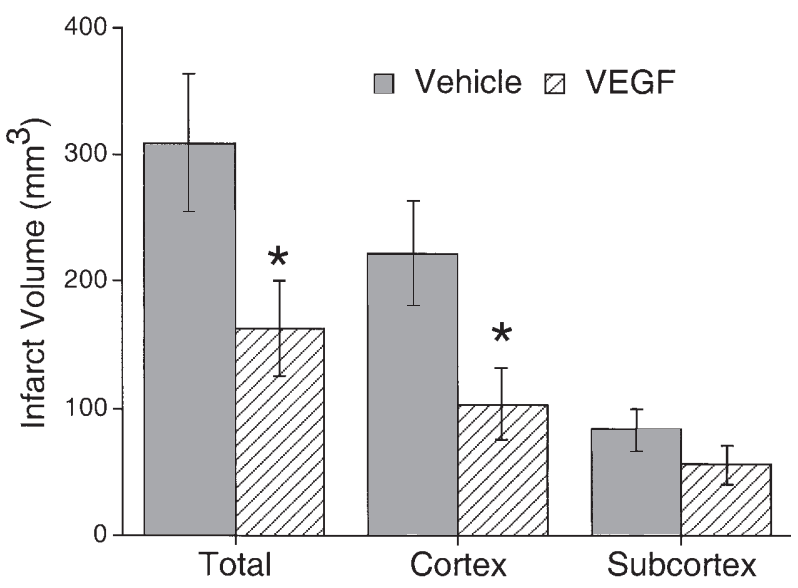

Fig. 2. Bar graph showing infarct volumes in the cortical, subcortical, and total hemisphere of rats' brains 24 hours after temporary MCAO for groups treated with VEGF $(n=6)$ or vehicle $(n=7)$. Values are mean \pm SE. $* P<0.05$

into cortical and subcortical components, the cortical infarct volumes were still smaller in the VEGF group $\left(105 \pm 28\right.$ versus $\left.223 \pm 41 \mathrm{~mm}^{3}, P<0.05\right)$; however, the subcortical infarct volumes were not significantly different $\left(58 \pm 15\right.$ versus $\left.85 \pm 16 \mathrm{~mm}^{3}\right)$. In VEGFtreated animals the total and cortical infarct volumes were reduced $53 \%$ and $47 \%$, respectively, compared to vehicle-treated animals.

\section{Brain water content}

Brain water content was measured after temporary MCAO for animals treated with VEGF or vehicle (Fig. 3). In the hemisphere ipsilateral to the infarction, brain water content was significantly reduced in the outer region of animals receiving VEGF $(80.9 \pm 0.7 \%$ versus $83.3 \pm 0.6 \%, P<0.05)$. There was a trend toward significance indicating a reduction in brain water content in the intermediate zone of animals treated with VEGF $(82.8 \pm 1.0 \%$ versus $83.7 \pm 0.9 \%$, $P=0.55)$. There were no significant differences between treatment groups in the core region or in the hemisphere contralateral to the infarction. 


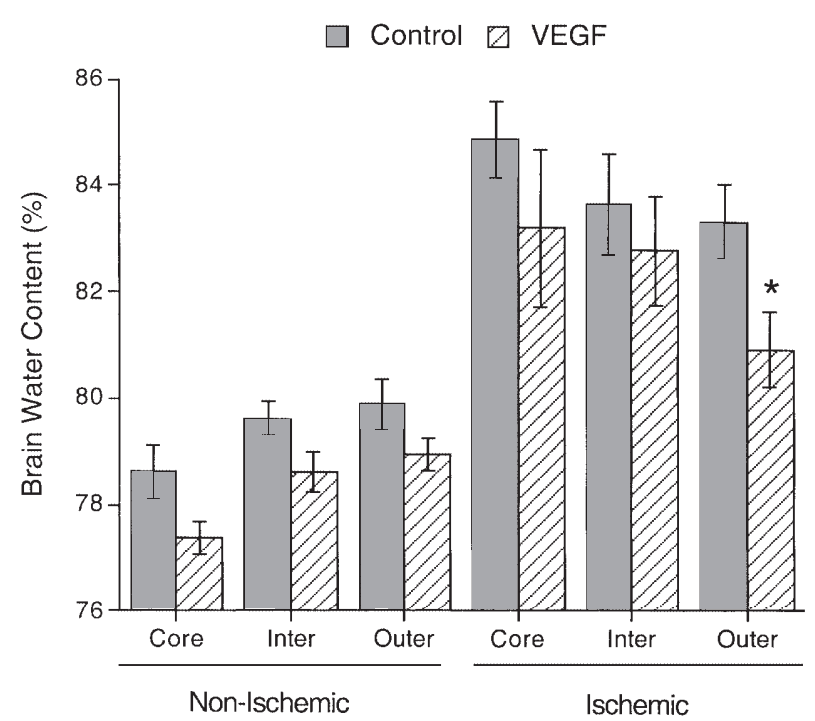

Fig. 3. Bar graph showing brain water content 24 hours after temporary MCAO for groups treated with VEGF or vehicle $(n=6$ in each group). Values are mean \pm SE. $* P<0.05$

\section{Discussion}

These data show that, although cerebral blood flow was not increased by intraventricular infusion of VEGF $_{165}$ at a concentration of $5 \mu \mathrm{g} / \mathrm{ml}$, infarct volume and brain edema were significantly reduced after temporary MCAO.

There is evidence that VEGF is a potential therapeutic agent for stroke. Topical application of VEGF to the cortical surface reduces infarct volume and brain edema after temporary MCAO in the rat [5], and intraventricular infusion of VEGF antibody increases infarct volume after temporary MCAO in the rat [1]. The current study also showed a beneficial effect of exogenous VEGF on infarct volume after transient MCAO but indicated that these effects were not mediated by altered cerebral blood flow (secondary to angiogenesis), but rather appear to be due to direct neuroprotection. The beneficial effect of VEGF on infarct volume was not offset by an increase in edema formation.

The dose of $\mathrm{VEGF}_{165}$ selected for this study was based on prior work by this laboratory showing that intraventricular infusion $(1 \mu \mathrm{l} / \mathrm{hr})$ at a concentration of $5 \mu \mathrm{g} / \mathrm{ml}$ was the threshold dose required to produce angiogenesis [4]. Higher dosing of $\operatorname{VEGF}_{165}(25 \mu \mathrm{g} /$ $\mathrm{ml}$ ) produced a larger increase in vessel density, but also led to bilateral ventriculomegaly, septal atrophy, and grossly enlarged vessels. In the present study, cerebral blood flow was not changed after infusion of
$\operatorname{VEGF}_{165}$ at a concentration of $5 \mu \mathrm{g} / \mathrm{ml}$. This may reflect the relatively modest increase in vessel density produced by this dose, and any increase in cerebral blood flow associated with this degree of angiogenesis may be too small to detect with the indicator fractionation technique. Another possibility is that intraventricular infusion of VEGF produces an increase in vessel density within the parenchyma of the brain without creating additional channels for collateral blood flow; in this situation the VEGF-induced vessels would be relatively isolated and unable to cause a net increase in cerebral blood flow.

The significant reduction in cortical infarct volume after temporary MCAO, without an increase in cerebral blood flow, suggests that VEGF has a neuroprotective effect in the setting of ischemia. The absence of a significant reduction in infarct volume in the subcortical region may be due to a greater distance from the lateral ventricle and a relatively smaller exposure to intraventricular VEGF. In addition, the poor collateral blood supply to this region makes it more vulnerable to ischemic injury [19].

VEGF has been found to have neuroprotective and neurotrophic properties in cultured neurons $[6,10,15$, 20] and organotypic explant cultures [14]. Normal cerebrospinal fluid production in the adult rat is approximately $120 \mu \mathrm{l} / \mathrm{hr}$. With an osmotic minipump infusion rate of $1 \mu \mathrm{l} / \mathrm{hr}$, the effective concentration of VEGF in the cerebrospinal fluid was $42 \mathrm{ng} / \mathrm{mL}$. This concentration is similar to other reports, in which neurotrophic and neuroprotective effects are associated with VEGF concentrations between 10 and $100 \mathrm{ng} / \mathrm{mL}[6,15,20]$.

VEGF has capillary permeability effects as well as being neuroprotective and angiogenic. Thus, it is possible that any beneficial effect on infarct volume with focal cerebral ischemia might be offset by an increase in vasogenic edema. Although our previous study on non-ischemic rats did not find any increase in brain water content following intracerebroventricular infusion of $\mathrm{VEGF}_{165}$ at a concentration of $5 \mu \mathrm{g} / \mathrm{ml}$ [4], it is possible that VEGF might produce edema in an injured brain. Indeed, there is evidence that endogenous VEGF expression following transient ischemia contributes to edema formation [16]. However, in the current study, we did not find an increase in brain edema in the VEGF-treated rats after 22 hours of reperfusion. In fact there was a significant reduction in edema formation in the outer zone. Thus, it appears that any increase in brain edema due to enhanced 
capillary permeability is overwhelmed by the reduction in edema because of a decreased infarct size.

This study has several limitations. First, human recombinant VEGF was used in a rodent model. It is possible that human VEGF has effects in rats that would not be present in humans. Second, the indicator fractionation $\mathrm{CBF}$ measurement technique is quantitatively very accurate but does not have a high degree of anatomic resolution. Thus, there may have been changes in $\mathrm{CBF}$ in small regions of the brain after infusion of VEGF that were not detected in this study.

In conclusion, we have previously shown that there is a narrow range where intracerebroventricular infusions of VEGF can induce angiogenesis without inducing significant ventriculomegaly. Infusion of VEGF in that range does reduce infarct size but that effect appears to be due to a direct neuroprotection rather that angiogenesis.

\section{References}

1. Bao WL, Lu SD, Wang H, Sun FY (1999) Intraventricular vascular endothelial growth factor antibody increases infarct volume following transient cerebral ischemia. Chung Kuo Yao Li Hsueh Pao 20: 313-318

2. Baumgartner I, Pieczek A, Manor O, Blair R, Kearney M, Walsh K, Isner JM (1998) Constitutive expression of phVEGF165 after intramuscular gene transfer promotes collateral vessel development in patients with critical limb ischemia. Circulation 97: 1114-1123

3. Freedman SB, Isner JM (2001) Therapeutic angiogenesis for ischemic cardiovascular disease. J Mol Cell Cardiol 33: 379_ 393

4. Harrigan M, Ennis S, Masada T, Keep R (2002) Intraventricular infusion of vascular endothelial growth factor promotes cerebral angiogenesis with minimal brain edema. Neurosurgery 50: $589-598$

5. Hayashi T, Abe K, Itoyama Y (1998) Reduction of ischemic damage by application of vascular endothelial growth factor in rat brain after transient ischemia. J Cereb Blood Flow Metab 18: 887-895

6. Jin KL, Mao XO, Greenberg DA (2000) Vascular endothelial growth factor rescues HN33 neural cells from death induced by serum withdrawal. J Mol Neurosci 14: 197-203

7. Longa E, Weinstein P, Carlson S, Cummins R (1989) Reversible middle cerebral artery occlusion without craniectomy in rats. Stroke 20: 84-91

8. Losordo D, Vale P, Symes J, Dunnington C, Esakof D, Maysky M, Ashare A, Lathi K, Isner J (1998) Gene therapy for myocardial angiogenesis: initial clinical results with direct myocardial injection of phVEGF165 as sole therapy for myocardial ischemia. Circulation 98: 2800-2804

9. Menzies S, Betz A, Hoff J (1993) Contributions of ions and albumin to the formation and resolution of ischemic brain edema. J Neurosurg 78: 257-266
10. Oosthuyse B, Moons L, Storkebaum E, Beck H, Nuyens D, Brusselmans K, Van Dorpe J, Hellings P, Gorselink M, Heymans S, Theilmeier G, Dewerchin M, Laudenbach V, Vermylen P, Raat H, Acker T, Vleminckx V, Van Den Bosch L, Cashman N, Fujisawa H, Drost MR, Sciot R, Bruyninckx F, Hicklin DJ, Ince C, Gressens P, Lupu F, Plate KH, Robberecht W, Herbert JM, Collen D, Carmeliet P (2001) Deletion of the hypoxiaresponse element in the vascular endothelial growth factor promoter causes motor neuron degeneration. Nat Genet 28: 131138

11. Rosengart T, Lee L, Patel S, Kligfield P, Okin P, Hackett N, Isom O, Crystal R (1999) Six-month assessment of a phase I trial of angiogenic gene therapy for the treatment of coronary artery disease using direct intramyocardial administration of an adenovirus vector expressing the VEGF121 cDNA. Ann Surg 230: 466-470

12. Rosengart T, Lee L, Patel S, Sanborn T, Parikh M, Bergman G, Hachamovitch R, Szulc M, Kligfield P, Okin P, Hahn R, Devereux R, Post M, Hackett N, Foster T, Grasso T, Lesser M, Isom O, Crystal R (1999) Angiogenesis gene therapy: phase I assessment of direct intramyocardial administration of an adenovirus vector expressing VEGF121 cDNA to individuals with clinically significant severe coronary artery disease. Circulation 100: 468-464

13. Rosenstein J, Mani N, Silverman W, Krum J (1998) Patterns of brain angiogenesis after vascular endothelial growth factor administration in vitro and in vivo. Proc Natl Acad Sci 95: 7086-7091

14. Silverman WF, Krum JM, Mani N, Rosenstein JM (1999) Vascular, glial and neuronal effects of vascular endothelial growth factor in mesencaphalic explant cultures. Neuroscience 90: 1529-1541

15. Sondell M, Lundborg G, Kanje M (1999) Vascular endothelial growth factor has neurotrophic activity and stimulates axonal outgrowth, enhancing cell survival and Schwann cell proliferation in the peripheral nervous system. J Neurosci 19: 5731-5740

16. van Bruggen N, Thibodeaux H, Palmer JT, Lee WP, Fu L, Cairns B, Tumas D, Gerlai R, Williams SP, van Lookeren Campagne M, Ferrara N (1999) VEGF antagonism reduces edema formation and tissue damage after ischemia/reperfusion injury in the mouse brain. J Clin Invest 104: 1613-1620

17. Van Uitert R, Levy D (1978) Regional brain blood flow in the conscious gerbil. Stroke 9: 67-72

18. Williams J, Jones S, Bryan R (1991) Vascular responses of choroid plexus during hypercapnia in rats. Am J Physiol 260: R1066-R1070

19. Yang G, Betz A (1994) Reperfusion-induced injury to the bloodbrain barrier after middle cerebral artery occlusion in rats. Stroke 25: 1658-1665

20. Yourey PA, Gohari S, Su JL, Alderson RF (2000) Vascular endothelial cell growth factors promote the in vitro development of rat photoreceptor cells. J Neurosci 20: 6781-6788

21. Zachary I, Mathur A, Yla-Herttuala S, Martin J (2000) Vascular protection: a novel nonangiogenic cardiovascular role for vascular endothelial growth factor. Arterioscler Thromb Vasc Biol 20: 1512-1520

Correspondence: M. R. Harrigan, M.D., Department of Neurosurgery, University of Michigan Health System, 1500 E. Medical Center Drive, Room 2128 Taubman Center, Campus Box 0338, Ann Arbor, MI 48109-0338. 